\title{
Global TIES: Ten Years of Engineering for Humanity
}

\author{
Mandy Bratton \\ Executive Director, Global TIES \\ Jacobs School of Engineering \\ University of California, San Diego \\ mbratton@ucsd.edu
}

\begin{abstract}
Founded in 2004, Global TIES - Teams in Engineering Service at the University of California, San Diego is a nationally recognized humanitarian engineering and social innovation program. In Global TIES, student-led, faculty-advised, interdisciplinary teams of undergraduate students earn academic credit for designing engineering and technology solutions in partnership with local and global nonprofit organizations. Data suggest that participation in Global TIES has a positive impact on students on a number of academic and developmental variables, including many of the professional and technical skills recommended by the Accreditation Board for Engineering and Technology. These findings, as well as the program's history, mission, and curriculum, are described. Best practices developed and lessons learned over the program's first decade are also discussed.
\end{abstract}

Index Terms - service learning, humanitarian engineering, engineering education, social innovation, international education

\section{INTRODUCTION}

Earlier this year, a group of engineering deans and educators gathered at the National Academy of Engineering (NAE) to craft a response to President Barack Obama's urgent call to increase the number and diversity of students graduating with engineering degrees and to fortify them the skills they will need to meet $21^{\text {st }}$ century challenges. The meeting, entitled "Educating Engineers to Meet the Grand Challenges," produced a collective commitment on the part of colleges and universities to graduate a new generation of engineers, one that will be prepared to meet the societal challenges that have been alternately articulated by the White House Strategy for American Innovation, the NAE's Grand Challenges for Engineering, and the United Nations (UN) Millennium Development Goals. Specifically, the signatories have agreed to collectively graduate a minimum of 10,000 students over the next ten years who will have exposure, if not expertise, in five crucial, overlapping domains:

- Project-based learning related to one or more of the NAE Grand Challenges;

- Experiential learning that includes interdisciplinary experience;

- Entrepreneurship and innovation experience;

- Cross-cultural or global experience;

- Development of social conscience through service learning (NAE, 2014). ${ }^{1}$

The task of transforming the undergraduate engineering experience is a formidable one. In their persuasive report on behalf of the American Society for Engineering Education (ASEE), Jamieson and Lohmann (2009) astutely point out that how we teach is at least as important as what we teach. ${ }^{2}$ The most compelling material will fall on deaf ears in today's engineering 
classrooms, if today's students do not perceive it as relevant and engaging. Moreover, the most effective learning environments grow out of a concern for both content and learning, and they reflect a thoughtful integration of curriculum, instruction, and assessment of learning outcomes (Jamieson and Lohmann, 2009).

Fortunately, the paradigm has begun to shift in terms of the undergraduate engineering curriculum and how it is delivered, and there are an increasing number of models for effectively engaging students in the five experiences described above. These include the NAE Grand Challenge Scholars Program, Engineers Without Borders, and Engineering Programs in Community Service (EPICS), among others. Moreover, there is growing evidence that integrating these innovations into the undergraduate curriculum not only enhances the depth and breadth of students' educational experiences, but also has a positive effect on recruitment and retention of engineering students, particularly women and underrepresented minorities (Kuh, Kinzie, Schuh, and Whitt, 2005). ${ }^{3}$ Global TIES - Teams in Engineering Service at the University of California, San Diego (UC San Diego) is one such innovation. The program's mission, its ten-year trajectory, academic and developmental impact on students, best practices, and lessons learned are described below.

\section{A Brief History of Global TIES}

Global TIES is a nationally recognized humanitarian engineering and social innovation program in which faculty-advised, interdisciplinary teams of undergraduate students design solutions in partnership with nonprofit organizations in greater San Diego and in developing countries around the world. Founded in 2004 as Teams in Engineering Service (TIES) and inspired by and initially modeled after the award-winning EPICS program at Purdue University, the Global TIES program has designed affordable and sustainable engineering and technology solutions in partnership with local chapters of organizations such as Habitat for Humanity, United Cerebral Palsy, and the National Federation for the Blind. Initial funding was provided by a National Science Foundation (NSF) grant to EPICS to seed engineering service learning programs at other universities, and Global TIES remains an active member of the EPICS University consortium. It is one of three campus programs that have earned UC San Diego a place on President Obama's Honor Roll of Higher Education Community Service for each of the past four years (http://www.nationalservice.gov/about/initiatives/). It has also been recognized by the Clinton Global Initiative University. A brief video about Global TIES, produced by UCSD-TV, may be viewed on the program's web site (http://globalties.ucsd.edu).

In 2010, in recognition of the growing need for students to have cross-cultural competence as well as a more global awareness of socially urgent needs for engineering and technology solutions, TIES expanded its mission to include partnerships with non-governmental organizations (NGOs) in developing countries. Rebranded as Global TIES, the program currently has projects with Gawad Kalinga in the Philippines, the Loloma Foundation in Fiji, and La Misión Children's Fund in Mexico, in addition to an array of sustainable community development projects with local nonprofit partners in greater San Diego. 


\section{Mission}

Global TIES has a broad, student-centered mission:

"Through a rigorous, experiential, project-based curriculum, focused on human-centered design, humanitarian engineering, and social innovation, educate a new generation of global citizens who are called upon to improve the human condition, and who can:

- Be a vital part of and lead interdisciplinary teams;

- Innovate and creatively problem-solve in context (organizational, community, global);

- Celebrate diversity and work cross-culturally;

- Design appropriate and sustainable solutions that have social as well as economic value."

As stated, the core mission of Global TIES is one of education. However, meeting the needs of partner nonprofit organizations is inextricably woven into the educational mission of the program. Through the focus on human-centered design and humanitarian engineering, students learn to see "clients" as "partners" without whose cooperation, designed solutions, no matter how innovative or affordable, cannot succeed in the long-term. The needs of partner organizations must be satisfactorily addressed in order for the relationship to flourish and the project to advance. Moreover, students are encouraged to use this relational context to redefine "service" as a reciprocal activity in which they may very well gain more than those they are purporting to serve. But it is essential that partners gain from the experience as well. Otherwise, service learning programs are at risk of squandering the time and good will that partner organizations invest in their students. In the absence of careful stewardship of relationships with organizational and community partners, service learning initiatives are at risk of devolving into exploitation.

\section{Curriculum}

The Global TIES program is currently rooted in a two-course curriculum. Global TIES students initially participate in a foundational design course, formerly called "Team Engineering," but recently reformulated and retitled as "Design for Development." This course introduces students to the practice of human-centered design and humanitarian engineering. Topics include contextual listening, needs and capacity assessment, stakeholder analysis, sustainable community development, social innovation, team development and leadership, project management, and ethical engagement with organizations and communities. Students collaborate with peers on "paper" design projects in partnership with a local nonprofit organization or a global NGO with local representation. These "paper" projects often serve as the basis for the longer-term projects and partnerships in the laboratory course, described below. Students typically take the design course prior to or concurrently with their first quarter of participation in the laboratory course.

Each section of the laboratory course, "Design for Development Lab," corresponds to one of the Global TIES program's long-term (multi-quarter) projects. In this course, students participate in small (8-15 students), faculty-advised teams that design, build, test, and deliver engineering and technology solutions for one of the program's nonprofit partners. Projects have included creating digital records systems for a local nursing home and free clinic, designing a kindergarten from a salvaged shipping container for a remote village in Fiji, and building a solar- 
powered water pump for a children's home in Mexico. Students may take the laboratory course for up to six quarters of academic credit, giving them a rare opportunity for start-to-finish design experience. Teams are vertically integrated, with students who are new to the project learning from more experienced students. This model creates a "leadership ladder" within Global TIES by which students rise into leadership positions on the team and within the program. Teams complete client presentations and continuity reports to provide for smooth transitions between academic quarters. Each team is advised by a faculty and/or technical advisor, as well as an undergraduate student with advanced training and experience in the program. Faculty advisors come primarily from within the school of engineering, but projects have also been advised by faculty from other schools, such as medicine, social sciences, and the arts and humanities. Technical advisors are practicing or retired professional engineers, who volunteer their time to the program.

As noted above, how courses are delivered is likely to be as important as course content in terms of engaging students. Global TIES courses are largely experiential and the technical material involved varies, appropriately, by project. However, there are some elements that are common to all projects and that research has indicated are crucial to student engagement and success:

- Problem-focused/project-based learning;

- Active, experiential learning;

- Collaborative learning;

- Field-based learning;

- Close faculty-student interaction;

- Interdisciplinary learning;

- Community and/or global engagement (Kuhn, Kinzie, Schuh, and Whitt, 2005). ${ }^{4}$

Moreover, the Global TIES program is closely aligned with the mission and strategic plan for both the engineering school and the university. This alignment has been crucial in garnering institutional support and the respect and participation of faculty and students. Global TIES courses may be used to fulfill technical or professional electives in nearly all of the engineering majors, including those in computer science. In addition, students may use the courses to partially fulfill requirements for the business minor. Strategic partnerships between Global TIES (which is housed in the engineering dean's office) and departments within the engineering school and across the campus have played a critical role in growing and diversifying the enrollment of the program.

\section{Program Outcomes}

\section{Participation}

Enrollment in the Global TIES program has grown dramatically since the early years of the program (Figure 1). In 2013-14, the total enrollment in the Global TIES courses was 709 students, the highest enrollment to date. (It should be noted that this number reflects combined course enrollment, and not individual students, as in any given quarter, students may be concurrently enrolled in both the design and laboratory course.) This represents a $175 \%$ increase over enrollment during the inaugural year of the program and a 130\% increase since 2008-09, the academic year before the program went "global". Multiple sections of both the design and laboratory course are currently offered every quarter. 
Historically, Global TIES has enrolled a significantly greater percentage of female students with engineering and technology majors than the national average reported by the NSF. Of the 1,665 students with engineering majors who have participated in the Global TIES program over the past decade, 488 or $29.3 \%$ have been women. Annual percentages have ranged from a low of $21.4 \%$ during the inaugural year of the program to a high of 35.6\% in 2013-14. (It should be noted that these percentages reflect individual female students with engineering and computer science majors. Female students with non-engineering majors regularly enroll in Global TIES, but are not reflected in these statistics.) During this same period, the percentage of women undergraduates enrolled in engineering schools across the nation ranged from a low of $16.3 \%$ in 2004 to a high of $18.6 \%$ in 2011, the last year for which data are publicly available (NSF, 2014). ${ }^{5}$ This trend constitutes a welcome but not wholly unexpected outcome of the Global TIES program. Similar trends have been found in EPICS and other course-based service learning programs. Moreover, there is a growing body of evidence that gender differences exist in the value that people place on engaging in work that directly benefits society, with women more likely than men to be attracted to work that has a clear social purpose (Margolis \& Fisher, 2002; Lubinski \& Benbow, 2006; Eccles, 2007). ${ }^{6-8}$ The focus on human-centered design, humanitarian engineering, and social innovation that characterizes the Global TIES program likely appeals to female engineering majors who are looking for ways to apply their skills for social good.

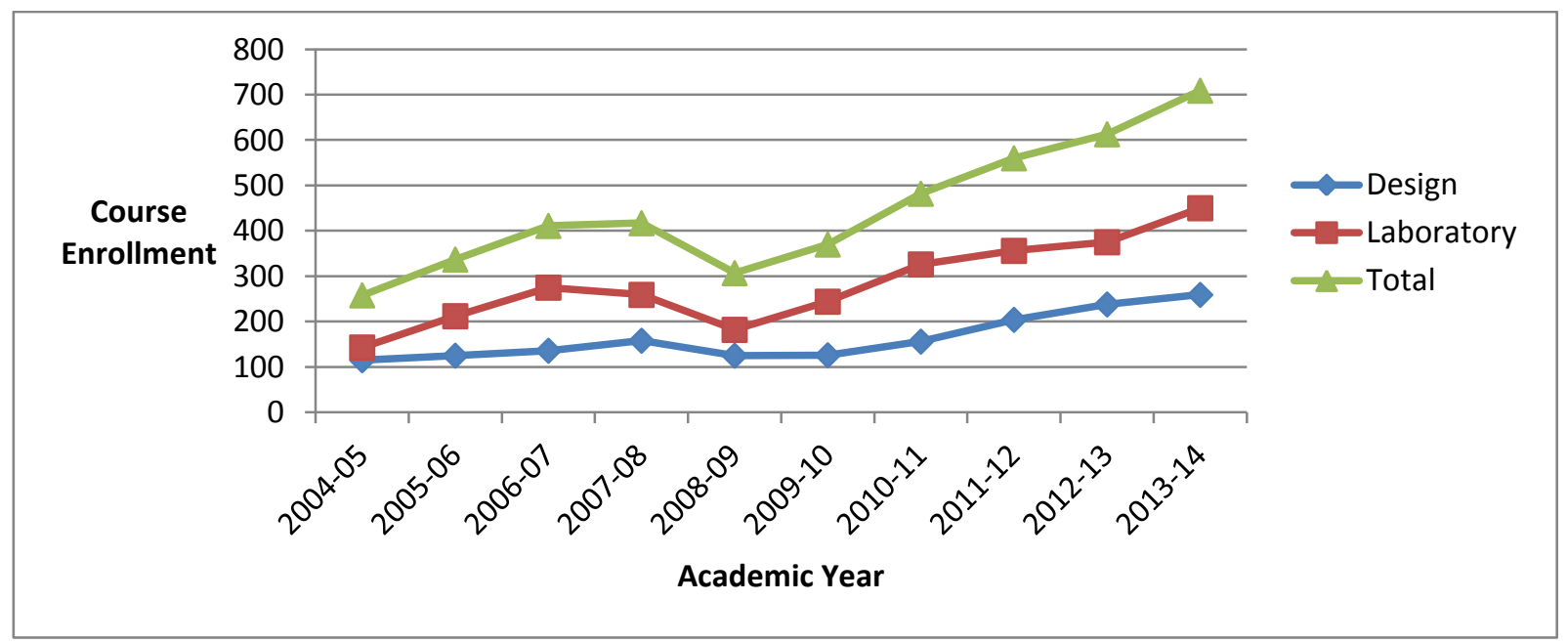

FIGURE 1

GLOBAL TIES COURSE ENROLLMENT BY ACADEMIC YEAR

\section{Academic Outcomes}

In an effort to evaluate the impact of the Global TIES program, students enrolled in the laboratory course were asked to complete a survey at the beginning and end of a recent quarter. Twenty-six of the 62 students enrolled at the end of the add period took both the pretest and posttest, yielding a response rate of $42 \%$.

Twenty of the students $(76.9 \%)$ who took the posttest were male and six $(23.1 \%)$ were female. A majority of students (88.5\%) identified their ethnicity as "Not Hispanic/Latino(a)." In terms of race, eleven students (42.3\%) reported their race as "White," and nine students (34.6\%) reported their race as "Asian American." Similar results were found on the pretest, and these 
percentages approximated the demographic profile of the course, with the exception that women and Asian Americans were slightly underrepresented. All of the respondents had engineering majors, and all but three were completing their first quarter in the program.

Of particular interest was the impact the program may have had on students' self-efficacy beliefs with regard to the practice of engineering. Self-efficacy has been described as an individual's belief in his or her capacity to execute domain-specific behaviors (Bandura, 1977; 1997). ${ }^{9-10}$ Students were asked to complete the Engineering Self-Efficacy Scale (ESES) (Bratton, 2009). ${ }^{11}$ The ESES uses the Accreditation Board for Engineering and Technology's (ABET) learning outcomes as the behavioral domain. Students were asked to indicate how confident they felt in their ability to complete each of the 13 learning outcomes. Students indicated their degree of confidence utilizing a seven-point scale with these anchors: " 1 - No Confidence" and "7 Complete Confidence." Students were able to select "NA" if they felt that the item did not pertain to them. This option was included given that students with non-engineering majors were enrolled in the course.

As Table 1 indicates, respondents scored significantly higher on the posttest for eight of the 13 items on the ESES. Students reported greater self-efficacy in design, identifying and formulating problems, solving problems, making professional presentations, writing professional reports, using engineering techniques, skills, and tools, and understanding the impact that technology can have on society. Moreover, a statistically significant difference was also found on ESES Total Score, which represents the sum of the item scores while controlling for missing responses. Item means and standard deviations are reported in Table 1. Although the sample was quite small and the study did not have the benefit of a control or comparison group, these results are remarkable given that 22 of the 26 respondents $(84.6 \%)$ identified themselves as seniors who likely entered the program with highly developed skills.

\section{TABLE I}

MEAN RESPONSES ON ENGINEERING SELF-EFFICACY SCALE

\begin{tabular}{|c|c|c|c|c|c|}
\hline \multirow[t]{2}{*}{ ABET Learning Outcome } & \multicolumn{2}{|l|}{ Pretest } & \multicolumn{2}{|c|}{ Posttest } & \multirow[t]{2}{*}{ t score } \\
\hline & Mean & S.D. & Mean & S.D. & \\
\hline Apply mathematics, physics, and/or engineering to a project. & 5.15 & 1.17 & 5.48 & 1.01 & 1.61 \\
\hline Design a system, component, or process to desired specifications. & 5.30 & 0.91 & 5.67 & 0.92 & $2.43 *$ \\
\hline Function on a multi-disciplinary team. & 6.15 & 0.77 & 6.22 & 0.85 & .40 \\
\hline Identify and formulate engineering problems. & 5.15 & 1.26 & 5.74 & 0.86 & $3.31 * * *$ \\
\hline Solve engineering problems. & 5.11 & 1.12 & 5.63 & 0.84 & $2.42 *$ \\
\hline Understand professional and ethical responsibilities. & 5.78 & 0.93 & 5.93 & 0.87 & .72 \\
\hline Make professional presentations to others. & 5.22 & 1.45 & 5.96 & 1.02 & $2.92 * *$ \\
\hline Write professional reports. & 4.59 & 1.45 & 5.52 & 1.05 & $3.28 * * *$ \\
\hline Understand the impact that technology can have on society. & 5.74 & 0.90 & 6.33 & 0.83 & $3.05 * * *$ \\
\hline Understand the issues facing, community, country, and the world. & 5.48 & 0.89 & 6.04 & 1.02 & $2.31 *$ \\
\hline Use the techniques, skills, and tools necessary to practice profession. & 5.37 & 0.84 & 5.81 & 1.04 & $2.37 *$ \\
\hline $\begin{array}{l}\text { Work effectively with individuals of different economic, social, and racial } \\
\text { or ethnic backgrounds. }\end{array}$ & 6.35 & 0.63 & 6.35 & 0.80 & .00 \\
\hline Recognize the importance of lifelong learning. & 6.69 & 0.55 & 6.50 & 0.81 & 1.15 \\
\hline Total Engineering Self-Efficacy Score (sum of item scores) & 72.07 & 8.15 & 76.70 & 9.97 & $2.62 *$ \\
\hline
\end{tabular}

$\mathrm{N}=26 ; * \mathrm{p} \leq .05, * * \mathrm{p} \leq .01, * * * \mathrm{p} \leq .005$ 


\section{Developmental Outcomes}

The results of subsequent surveys suggest that participation in the Global TIES program positively impacts students in other important ways as well. Students routinely report selfperceived gains in leadership skills, collaboration skills, commitment to future service, knowledge and understanding of global issues, appreciation for diversity, and confidence in their ability to "make a difference in the world."

In a recent quarter, 87 students enrolled in the laboratory course were asked at the beginning and end of the quarter to indicate the extent to which they agreed with a number of statements about their skills and abilities. Each item was followed by a five-point scale, anchored by "1Strongly Disagree" and "5-Strongly Agree." Forty-five of the students returned useable surveys at the end of the quarter, yielding a response rate of $51.7 \%$. As with the previous survey, students were asked to create a unique codename on the first survey and then to recall it on the second survey, in order to enable a comparison of their responses while still preserving the anonymity of the data. Unfortunately, in this case, this system yielded too few matches for the results to be analyzed by inferential methods. However, percentages of students endorsing "Agree" or "Strongly Agree" for each item on each occasion are reported in Table II.

\section{TABLE II}

PERCENTAGES OF GLOBAL TIES PARTICIPANTS INDICATING AGREEMENT WITH DEVELOPMENTAL ITEM

\begin{tabular}{lcc}
\hline Item & $\begin{array}{c}\text { Percentage at } \\
\text { Beginning of Quarter (N=87) }\end{array}$ & $\begin{array}{l}\text { Percentage at } \\
\text { Conclusion of Quarter (N=45) }\end{array}$ \\
\hline $\begin{array}{l}\text { Leadership } \\
\quad \text { I have the ability to lead a group of people. }\end{array}$ & 71.4 & 80.0 \\
$\quad$ I know how to influence others and gain support for an idea. & 63.2 & 84.1 \\
Collaboration & 83.7 & 88.9 \\
$\quad$ I can communicate well with others. & 82.8 & 86.4 \\
$\quad$ I am able to gain the trust and respect of others in a group. & 83.9 & 97.8 \\
Appreciation for Diversity & & 93.3 \\
$\quad$ I enjoy meeting people who come from backgrounds different from my own. & 95.6 \\
$\quad$ Having people from different backgrounds usually strengthens the effectiveness \\
$\quad$ of a team.
\end{tabular}

Evaluations of the Global TIES program have often also included "post-only" items that are asked only at the end of the quarter. These items are designed to encourage students to reflect on how their experience in the program may have affected them and whether they would recommend the program to other students. Students are asked to indicate their agreement with each item utilizing the same five-point scale described above. Results from a recent quarter are reported in Table III. 
TABLE III

PERCENTAGES OF GLOBAL TIES PARTICIPANTS INDICATING AGREEMENT WITH "POST-ONLY" ITEM

\begin{tabular}{lc}
\hline \multicolumn{1}{c}{ Item } & $\begin{array}{c}\text { Percentage at Conclusion } \\
\text { of Quarter (N=45) }\end{array}$ \\
\hline I have a better understanding of the role of a professional in my field. & 84.1 \\
I have increased my awareness of problems facing my community, country, and the world. & 86.4 \\
My interest in working with people from diverse backgrounds has increased. & 86.4 \\
I have learned to apply concepts from my courses to real situations. & 88.6 \\
I have become more interested in engineering and/or technology & 90.9 \\
I would recommend the Global TIES program to other students. & 93.2 \\
\hline
\end{tabular}

As Table III indicates, nearly nine in ten students $(88.6 \%)$ reported that they had learned to apply their knowledge to real world settings. Moreover, slightly more than nine in ten $(90.9 \%)$ reported that they became more interested in engineering and technology as a result of their participation in the program. An even larger percentage (93.2\%) reported that they would recommend the Global TIES program to other students.

There are other, less conventional ways of measuring program impact. A number of Global TIES students have received recognition for their project-related work, such as awards from UC San Diego's Bernard and Sophia Gordon Engineering Leadership Center. Teams routinely compete and prevail in university-wide and regional social innovation design competitions. And nine of the 27 students representing UC San Diego at the 2014 Clinton Global Initiative University were Global TIES students.

More deeply engaged students are likely to become more deeply engaged and devoted alumni. While the participation rate in alumni giving across a wide variety of institutions hovers between $9-10 \%$ (Schipp, 2013), ${ }^{12} 41 \%$ of the students who have participated in Global TIES have made at least one gift to UC San Diego. These gifts have ranged in size from $\$ 10$ to $\$ 12,000$. The largest alumni gift to the program allowed a team of students to travel to the Philippines to deploy their solar-powered streetlamp prototype. Given the relative youth of the program's alumni, their generosity is commendable. One recent graduate summed up her reason for support of the program in this way:

"I have found a passion that will allow me to help others for the rest of my life. It's not just about engineering. It's about working with real people on real problems and solving them to help a community succeed. Words are not enough to express my gratitude for what Global TIES has offered me."

\section{An In-DePth Look at One Project}

In March 2010, the executive director of the Global TIES program traveled to the Philippines, where she met with the leaders and staff of the NGO Gawad Kalinga (GK) (http://www.gk1world.com/home). Founded in 2003, GK has an ambitious mission: "ending poverty for five million families by 2024." ${ }^{13}$ It enacts this mission through building sustainable communities across the Philippines for those who are homeless or living in substandard conditions. Or more accurately, it acquires the land and building materials, and assists the poor in building their own communities, along with building their self-esteem and hope for the future. 
Impressed by what she witnessed, the executive director launched a new project partnering with this inspiring NGO. GK has a fund-raising arm of its organization in the United States, headquartered in San Diego. This allowed students to interact not only via Skype with GK representatives in the Philippines, but also with local representatives who could help provide feedback on designs.

The new team first set out to learn all that it could about its partner and the context in which it operated. This process was facilitated by interaction with the representatives of GK in San Diego and Manila, but perhaps more significantly, by the leadership of several of the team members themselves. A number of Filipino students and students of Filipino descent joined the team, eager to give back to the Philippines. They enthusiastically introduced their teammates to the history, food, and music of the Filipino culture.

Initial projects focused on improving the design of GK homes, making them more structurally sound and environmentally sustainable. A particular problem that GK faced was the number of roofs lost to high winds during frequent typhoons. The Global TIES team set to work on an improved roof design that could be integrated into new construction without significantly raising costs. It also designed a typhoon strap that could more securely join existing roofs to the walls of homes. Other projects included water filtration and rainwater catchment systems.

In 2011, the Global TIES program hosted a visit by Tony Meloto, the founder of GK and winner of the Skoll World Forum Award for Social Entrepreneurship. Students were mesmerized and energized by his talk, and "Tito Tony", as he is known in the Philippines, subsequently invited the team to a GK fundraising event in Las Vegas where he highlighted their work and introduced them to the Vice-President of the Philippines, Jejomar Binay. At that time, GK was in the process of launching the second phase of its "Development Roadmap," focused on "social artistry" or social entrepreneurship. In this phase, GK was building the first of what they hope will be several "Centers for Social Innovation" throughout the Philippines. These centers will strive to inspire Filipinos to create social enterprises that will generate employment for themselves and their neighbors. To this end, GK was eager to partner with universities, such as the UC San Diego, and programs, such as Global TIES, to generate ideas and prototypes for exhibition at what is known as the "Enchanted Farm" (http://gk1world.com/gk-enchanted-farm).

The Global TIES students enthusiastically embraced this challenge. They designed, built, and tested a solar-powered streetlamp that could be utilized to reduce GK communities' dependence on an expensive, often unreliable, and in some areas, unavailable electrical grid. In June 2013, a team of students traveled to the Philippines for a week to assemble and erect their prototype. As mentioned above, this deployment trip was underwritten by an alumnus of the Global TIES program with matching funds from his employer. Additional support was provided by the UC San Diego's Social Innovation Fund, which awards grants to students through a competitive process.

On arrival in Manila, the students scoured the city in search of the hardware and electronic components that were too cumbersome to carry from the United States or were unlikely to make it successfully through customs and security at the airports. Then they huddled into a "jeepney" (a jeep with two parallel benches in the rear for passengers; a popular mode of transportation in the Philippines) for the three-hour trip from Manila to the town of Angat in Bulacan Province, the site of the Enchanted Farm. At the farm, they were met by "Tito Tony" Meloto and members of his staff. The students participated in an orientation about the vision and mission of the Enchanted Farm, and at dawn the next morning, helped the local villagers plant crops. Then they 
began work on their prototype, putting in twelve-to-fourteen hour days - soldering, painting, assembling, waterproofing, digging, mixing and pouring concrete - and addressing the many unanticipated problems that inevitably accompany real-world humanitarian engineering. They finished erecting the prototype just a few hours before sunset on their last full day at the farm, and then waited anxiously to see if it would work. The lamp turned on at twilight as designed, an event accompanied by cries of jubilation from the students, GK staff, and villagers. The students with their successful prototype can be seen in Figure 2.

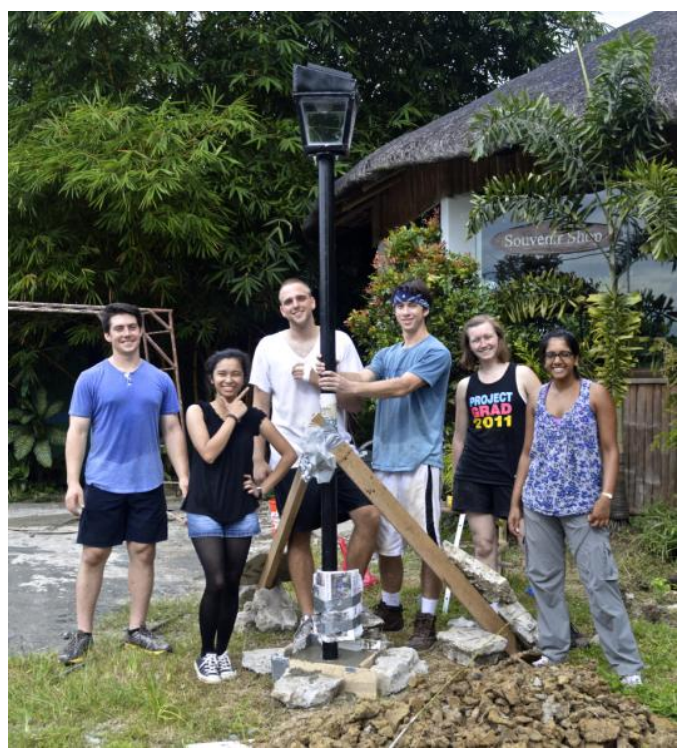

FIGURE 2

GLOBAL TIES STUDENTS WITH SOLAR-POWERED STREETLAMP PROTOTYPE AT GAWAD KaLINGA'S ENCHANTED FARM IN ANGAT, BULACAN, PHILIPPINES

Students were asked to reflect on their experience upon their return to the United States. One student wrote:

"This trip forced everyone to step far outside of the assumptions of physics problems or construction work in suburban California. When challenges are new they require creativity just as much as expertise. Offering even one of these made me valuable when we hit roadblocks (at every step of the process) and will make me valuable in any job I may interview for."

But students learned more than self-efficacy; they learned compassion:

"More than anything, I was reminded how truly lucky I am to have been born into the life I have. Yes, I have worked very hard for everything I have accomplished, but that doesn't mean I've worked very hard in the grand scheme of things. Many others continue to work way harder than I do, and they will never earn the material comfort that I was born with, or the knowledge that I have gained by the age of 19. I've always known this, but it's more overwhelming when the fact is staring you in the face. I know my future will be meaningless unless I work to level the gap that is so apparent overseas." 
The team is currently engaged in designing, building, and testing a new solar-powered streetlamp prototype and plans to make a return trip to the Philippines in 2015.

\section{Best Practices}

During its first decade, Global TIES has developed or adopted a number of "best practices" in terms of student engagement, such as project-focused, collaborative, interdisciplinary, fieldbased, and community-oriented service learning. Some of these practices have been described above. In addition, Global TIES tries to foster:

\section{Close Faculty-Student Interaction}

Perhaps one of the most appealing and rewarding features of the Global TIES program, for students and faculty alike, is the opportunity for close faculty-student interaction. The size of the teams in the laboratory course resembles the class size of a graduate seminar. (The optimal size for a team varies by project, but appears to fall between eight and fifteen students. If the team is too small, students begin to feel overwhelmed and frustrated, and productivity suffers. If the team is too large, students find it difficult to find a time to meet outside of class, and a diffusion of responsibility can occur, in which students lose track of who is accountable for what. Matching the size of the team to the scope and nature of the project and encouraging students to engage in careful planning at the beginning of each quarter can help to prevent and address these issues.) The relative small team size provides an invaluable opportunity for an undergraduate to regularly engage on a "first-name basis" with a faculty member and/or technical advisor. Faculty and technical advisors meet with student teams weekly, and travel with students to visit nonprofit partners and project sites. They often participate in "team-bonding" events, social activities held at the beginning of each quarter designed to catalyze the process of team development. In at least one case, a technical advisor even allowed students to construct a prototype in his garage! Global TIES faculty and technical advisors get to know individual students and their work on a deeper level than they would in large lecture course. They are in an excellent position to write detailed letters of recommendation for students for employment or admission to graduate school. Many Global TIES students stay in touch with their faculty and technical advisors, and their teammates, after graduation.

\section{Cross-Cultural Experiences}

Consonant with its mission, Global TIES strives to partner with nonprofit organizations that work with underserved communities. International projects are inherently cross-cultural and focus on underserved communities in developing countries. But even domestic projects are designed to provide students with opportunities to work with others whose racial, ethnic, and economic background, or abilities, may be very different from their own. Global TIES students have designed educational game apps for an academic enrichment center in a low-income housing development, created and delivered environmental education lessons in elementary, middle, and high schools in underserved neighborhoods, and adapted toys for children with special needs.

Students must be prepared to effectively and respectfully engage with these communities. General preparation occurs as part of the "Design for Development" course, in which students learn the importance of engineering in partnership with a community as opposed to creating designs based on their well-intentioned but sometimes initially ill-informed ideas of what a community needs. More project-specific preparation occurs on "Design for Development Lab" 
teams. For instance, the team who traveled to the Philippines engaged in intensive pre-departure training provided by the university's international center. Moreover, as noted above, in the three years leading up to the trip, Filipino students on the team taught their teammates basic phrases in Tagalog and introduced them to aspects of Filipino culture, politics, food, and music.

\section{Integrated, Experiential Course Structure}

As described above, Global TIES currently consists of an integrated two-course curriculum. The "Design for Development" course serves as a "feeder" of project ideas, designs, and students for the "Design for Development Lab." It also helps prepare students for the work of designing, iterating, building, testing, and deploying prototypes that takes place in the laboratory course. In a theory-intensive curriculum, these experiential courses serve as an important, practice-oriented bridge between foundational engineering courses and the capstone senior design project.

Course credit is the currency of academia, and academic rigor is not incompatible with service learning. Awarding course credit helps attract students to the program and ensures their investment even in light of mounting demands from their other courses. It also signals to students and faculty alike that the commitment of time and effort involved in Global TIES is commensurate with other courses. Credit is awarded for learning, not service. Students are required to complete a number of academic assignments throughout the quarter, including design project plans and budgets, goals and objectives, weekly progress reports, peer evaluations, and posters, presentations, and continuity reports for their client organization. There are also reflection assignments (described in greater detail below). Learning outcomes and the bases for evaluation are clearly articulated in the syllabi for both courses.

\section{Student Reflection}

Students in both the "Design for Development" course and the "Design for Development Lab" are encouraged to reflect on their work in order to consolidate their learning and better understand the "client" and context for their particular project. Unlike more technically oriented assignments, such as weekly progress reports and quarterly presentations and continuity reports, reflections focus on learning about self and others. These reflection assignments are completed by individual students, as opposed to teams, and have taken a variety of forms, from end-of-thequarter essays to shorter answers to specific prompts.

Recently, students in the "Design for Development" course were asked to provide one-page essays to questions about their projects or other course material. These assignments, called "takeaways," occurred every two-to-three weeks and were designed to help students reflect on their experience in the course and identify any content that had made a particular impression or otherwise deepened their understanding of the material. In some cases, prompts were general in nature (e.g., "What is one thing you have learned so far and how might you apply this knowledge in the future?"). In other cases, prompts were more content-specific (e.g., "What skills do you think you need to develop and practice to effectively deal with the ethical dilemmas that you might encounter in the future?"). Students were asked to submit each "takeaway" online, and the instructor then replied to each submission with a brief, personalized response designed to encourage further reflection. In this way, the instructor was able to engage in a quarter-long, online dialogue with each student.

Reflection after a field experience is also vitally important. Field experience reflections can take the form of essays, journals, presentations, slideshows, or videos. The common requirement regardless of medium is that the student must demonstrate what he/she has learned from the field 
experience and how he/she plans to apply that learning in the future. Excerpts from some field experience reflections have been included above.

\section{Improvement-Oriented Ethos}

Global TIES also engages in reflection on a program level and strives to maintain an improvement-oriented ethos through the use of systematic evaluations. These evaluations are in addition to the course and teaching evaluations routinely administered by the university. As described above, evaluations by students focus on their perceptions of their technical and professional skills, including those recommended by ABET, as well as leadership skills, appreciation for diversity, commitment to future service, and ways in which the Global TIES program may deepen their understanding of material from other courses. Moreover, project teams meet regularly with representatives of their client organizations and client feedback is routinely solicited and integrated into the development of the projects and the conduct of the overall program. The data from these various evaluations, some of which are reported above, are analyzed and communicated to the program's various stakeholders through a diversity of media.

\section{LESSONS LEARNED}

Through a process that mirrors what Global TIES tries to teach students about human-centered design and social innovation, the program's leadership and supporters have engaged in - and continue to engage in - iteration informed by user feedback. After ten years, Global TIES remains - by design - a work in progress. A few of the most significant lessons learned over the past decade are outlined below:

\section{Institutional Commitment}

An institution considering the launch of a program like Global TIES might be under the impression that it has to first stockpile a small fortune, given the expense involved in small project-based courses and student travel. But in actuality, Global TIES operates on a very lean budget, particularly when one considers the number of students it serves. Teams receive a modest allocation per quarter for the development of prototypes, and individual students are required to pay a portion of their international travel costs. (The program also provides travel scholarships, so that international travel is not limited to those students who have the ability to pay.)

There are a number of viable ways in which programs like Global TIES can be financed. Global TIES receives most of its funding from the university and engineering school, in support of the courses it delivers, and then fills in any gaps with gifts and grants. Moreover, judicious stewardship of resources has ensured that the program will be serving students and communities for the foreseeable future.

A related but more essential ingredient for success has been institutional commitment. Funds for innovative initiatives can come from a variety of sources, but nothing can replace commitment from the leadership of the institution. Global TIES has been fortunate that the leadership of both the engineering school and the university recognize the value that the program adds to the undergraduate curriculum, as well as the role that it plays in enacting the educational and service aspects of the mission of UC San Diego. They also recognize that the skills that students develop in "high impact" programs such as Global TIES are precisely the ones that employers are seeking in university graduates (Hart Research Associates). ${ }^{14}$ Moreover, as noted 
above, the program likely plays a significant role in recruiting and retaining engineering students, particularly women.

\section{Leadership Capacities of Undergraduate Students}

By design, Global TIES has a lean organizational structure. The program is led by a full-time executive director (who also teaches in the program), and projects are advised by a combination of faculty and technical advisors. Faculty receive teaching credit commensurate with the number of projects and quarters that they advise, and technical advisors serve on a volunteer basis. Faculty and technical advisors appear to be attracted to the service mission of the program. They tend to be active in community or international development work, and often approach the program with their own ideas for new projects. The program also employs a part-time staff person who provides programmatic and administrative support (e.g., managing laboratories, developing course schedules, etc.).

The program relies heavily on undergraduate teaching assistants to help faculty advise and manage projects. These advanced students have participated on a Global TIES team for one or more quarters, usually in a leadership position, and provide a crucial link between the individual projects and the program's administration. Their responsibilities mirror those of graduate assistants on other campuses, and they spend an average of ten hours per week advising two projects in exchange for a modest hourly salary. Undergraduate students also provide leadership for the program's marketing efforts and technical support. This extension of the "leadership ladder," described above, increases students' sense of commitment to and ownership of the program and helps to conserve fiscal resources.

\section{Flexibility}

Global TIES provides students with the opportunity to engage in "real world" humanitarian engineering, with real clients, real deliverables, and real deadlines. These projects promise deeper learning than do more contrived engineering problems, but they also present challenges not found in traditional classroom settings. Flexibility on the part of everyone involved in the project is essential to its success. As noted above, the program is largely student-driven, and students are, by definition, engaged in a learning curve. Teamwork is often more rewarding, but always more complicated than working alone. Moreover, the aims and leadership of partner nonprofit organizations can change, and the organization's fortunes can rise and fall, often unexpectedly. Students quickly learn that "real world" engineering is not as tidy as solving the "problems at the end of chapter five." International travel poses particular challenges, given that conditions on the ground can change rapidly. Careful vetting of clients and planning and management of projects can help prevent these challenges, and provide the stability necessary to ensure a rich learning experience for students. But part of what students learn is how to deal with the dynamic landscape and complexities of "real world" engineering, how to negotiate and re-negotiate with clients, and how to innovate in and adapt to changing circumstances. These skills will serve them well in their future careers. 


\section{FUTURE DIRECTIONS}

Global TIES is looking forward to the next decade and has ambitious plans as well as a bright outlook for the future. Some of its plans for the near term are described below:

\section{Social Innovation Curriculum}

A new "global citizen sector" (Bornstein, 2007) ${ }^{15}$ is emerging in the world economy. Many of the engineering undergraduates who are in classes and laboratories today will likely be participating in this sector tomorrow. To better prepare them to succeed and lead in this emerging sector, Global TIES plans to expand its curriculum to include courses in social innovation and entrepreneurship. A foundational course, utilizing the NAE Grand Challenges as an organizing theme, is currently in development. This course will focus on the skills necessary to create sustainable, mission-driven enterprises that have social as well as economic value. These will include visioning, strategic planning, research and market analysis, creating quantifiable goals and objectives, developing action plans, fundraising, and evaluating impact. Students will be encouraged to create a proposal for a social enterprise that addresses one or more the NAE Grand Challenges, and that can be further developed in the engineering school's undergraduate incubator.

\section{Alumni Engagement}

Global TIES is also exploring ways to more deeply engage with alumni of the program. The creation of an alumni association is underway, and a few experienced alumni have been invited back to the program to serve as instructors and technical advisors. This seems like a natural extension of the vertical integration model and "leadership ladder," described above, in which experienced alumni can serve as professional role models and mentors for current students. Creating a network of students and alumni can facilitate the professional development and advancement of its members, as well as create a growing base of prospective donors for the program.

\section{University Partnerships}

Finally, the Global TIES program is actively exploring partnerships with universities in other countries with an eye toward creating collaborative projects. Advances in technology allow Global TIES students to easily communicate with and collaborate with students enrolled at universities in countries in which the program works. Collaborations with international institutions would enrich the cross-cultural experience of students at both universities and enhance local knowledge and support of the project. It is hoped that these partnerships would also facilitate faculty and student exchanges between institutions.

\section{CONCLUSION}

Humanitarian engineering programs have the potential to make the undergraduate engineering curriculum more engaging and relevant to students. Moreover, they are one way in which engineering schools can enact the collective commitment to graduate a greater number and diversity of students who are prepared to meet the challenges of the $21^{\text {st }}$ century, such as those articulated in the NAE Grand Challenges and the UN Millennium Development Goals. Global TIES is a time-tested model that has demonstrated promising results in terms of its impact on students' engagement, as well as on their academic and professional development. It seeks to 
provide undergraduate students with transformative learning experiences in which they develop their social conscience, a well as their technical skills. Thus, they are prepared to succeed and lead in an increasingly complex and inter-connected world as both professionals and global citizens. Global TIES students are guided by a well-known quotation that they learn when they first join the program, a saying that has most often been attributed to the late American cultural anthropologist, Margaret Mead: "Never doubt that a small group of thoughtful, committed citizens can change the world; indeed, it's the only thing that ever has."

\section{ACKNOWLEDGMENTS}

The author wishes to acknowledge Jeanne Ferrante, Ph.D., Professor of Computer Science and co-founder of Global TIES, Lilla Orr, the 2014-15 Global TIES Fellow in Humanitarian Engineering, and Kelsey Ellis, Class of 2013and Global TIES alumnus, for their contributions to this paper.

\section{REFERENCES}

${ }^{1}$ National Academy of Engineering (NAE). Memorandum of Understanding to President Obama: Educating Engineers to Meet the Grand Challenges. April 2014, Washington, DC.

${ }^{2}$ Jamieson, Leah H., and Lohmann, Jack R. Creating a culture for scholarly and systematic innovation in engineering education. American Society of Engineering Educators, (2009).

${ }^{3}$ Kuh, George D., Kinzie, Jillian, Schuh, John H., and Whitt, Elizabeth. Student Success in College: Creating Conditions That Matter. San Francisco, CA: Jossey-Bass, (2005).

${ }^{4}$ Kuh, George D. et al. Student Success in College: Creating Conditions That Matter.

${ }^{5}$ National Science Foundation (NSF). Women, minorities, and persons with disabilities in science and engineering (NSF 13-304). Washington, DC: National Science Foundation, (2013).

${ }^{6}$ Margolis, Jane, and Fisher, Allan. Unlocking the Clubhouse: Women in Computing. Cambridge, MA: Massachusetts Institute of Technology, (2002).

${ }^{7}$ Lubinski, David, and Benbow, Camilla P. Study of Mathematically Precocious Youth after 35 years: Uncovering Antecedents for the Development of Math-science Expertise. Perspectives on Psychological Science, 1 no. 4 (2006): 316-345.

${ }^{8}$ Eccles, Jacqueline S. Where Are All the Women? Gender Differences in Participation in Physical Science and Engineering, in Why Aren't More Women in Science? Top Researchers Debate the Evidence, edited by S. J. Ceci and W. M. Williams: 199-210. Washington, DC: American Psychological Association, (2007).

${ }^{9}$ Bandura, Albert. Self-efficacy: Toward a unifying Theory of Behavioral Change. Psychological Review, 84 no. 2 (1977) :191-215.

${ }^{10}$ Bandura, Albert. Self-efficacy: The Exercise of Control. New York, NY: Freeman, (1997).

${ }^{11}$ Bratton, Mandy. Measuring the Learning in Service Learning. Presentation at the National Conference on Service Learning in Engineering and Computing, Austin, TX: August 2009. 
International Journal for Service Learning in Engineering Special Edition, pp. 205-221, Fall 2014

ISSN 1555-9033

${ }^{12}$ Schipp, Dan. Startling Drop in Alumni Giving. John Grossman and Associates, (2013). http://www.jgacounsel.com/2013/08/startling-drop-in-alumni-giving/

${ }^{13}$ Gawad Kalinga Mission, accessed October 11, 2014. http://www.gk1world.com/NewOurVision

${ }^{14}$ Hart Research Associates. It Takes More Than a Major: Employer Priorities for College Learning and Student Success (2013). https://www.aacu.org/sites/default/files/files/LEAP/2013_EmployerSurvey.pdf

${ }^{15}$ Bornstein, David. How to Change the World: Social Entrepreneurs and the Power of New Ideas. New York, NY: Oxford, (2007). 